\title{
Body Image and Self-Esteem in Female College Students of Healthy Weight and Excess Weight: The Mediating Role of Weight Stigma
}

\author{
Carlie Smith, Jennifer Becnel*, \& Amanda Williams \\ School of Human Environmental Sciences, University of Arkansas, Fayetteville, AR \\ bttps:/ / doi.org/10.33697/ ajur.2019.025 \\ Students: crs020@uark.edu \\ FacultyAdvisors:*becnel@uark.edu, alw077@uark.edu
}

\begin{abstract}
Emerging adulthood is an important transition in which the development of lifelong behaviors emerge. Recent research suggests that women in college are particularly vulnerable to poor body image and low self-esteem. This is also a time of possible weight gain as individuals learn to eat and exercise on their own. These are important as body mass index (BMI) influences how women feel about themselves and how others view them. Thus, the purpose of the present study was to examine the associations between body image, self-esteem, and weight stigma among female college students of healthy weight and excess weight. Participants ( $\mathrm{n}=124 ; 83 \%$ White) were recruited to take a short survey administered online through Facebook advertisements and snowball sampling. Results reveled poorer body image and more experiences with weight stigma among individuals with excess weight. Additionally, weight stigma fully mediated the relationship between BMI and self-esteem as well as BMI and body image. Results were consistent with previous research noting the stigma and stereotypes associated with excess weight. Future work should examine these relationships in more diverse groups to identify those at greatest risk for negative self-concept for intervention.
\end{abstract}

\section{KEYWORDS}

Weight; Weight Stigma; Self-Esteem; Body Image; College Students; Women

\section{INTRODUCTION}

Emerging adulthood is a time full of transitions. Although this is a relatively new developmental period, it is a time that is crucial for the development of an individual. ${ }^{1}$ An emerging adult is no longer an adolescent, but they are not yet a full adult either. ${ }^{1}$ Between the ages of 18 to 25, emerging adults are just getting to know themselves and figure out how they will spend the rest of their lives. ${ }^{2}$ Approximately one-third of people attend college right after high school. It is known that college students are exposed to a variety of stressors. ${ }^{3,4}$ Considering that college students face increased stressors in the academic atmosphere, there is evidence to suggest that emerging adults are a group of people who are considered "at risk" for maladaptive behaviors including drinking and other risk taking behaviors as well as and internalizing and externalizing difficulties such as depression, anxiety, and risktaking behavior. ${ }^{5}$ Depression, anxiety, binge drinking, drug use, casual sex without protection, eating disorders, weight gain, and drunk driving are examples of risky behavior that are prevalent during the college years. ${ }^{5}$ These are particularly problematic considering that the behavioral patterns developed in the emerging adult years have the potential to impact health in adulthood. ${ }^{6}$

Theory: Emerging Adulthood and Identity Development

Moving from adolescence to adulthood is a significant developmental transition. This transition was well-structured for most until the mid-20 th century but has recently shifted to being unstructured. ${ }^{5}$ Many factors have contributed to a lack of transitional structure, including delayed age at marriage and parenthood. ${ }^{1}$ In other words, instead of early adulthood being a time of settling down and commitment in the form of marriage, it has become a time that is full of exploration. ${ }^{2}$ This exploration and change has made the late teens to early twenties a distinct developmental period in the lifespan, called emerging adulthood. ${ }^{1}$ Not only do young adults experience independence from normal social roles and expectations, but they also engage in identity exploration. ${ }^{7}$ Specifically, identity exploration becomes more distinct relative to adolescence. Erik Erikson has proposed the theory of psychosocial development where identity development is crucial for the transition from adolescence into adulthood. ${ }^{8}$ For long term success, emerging adults need to be confident and firm in their identity development and to form their identity as they explore of various paths. ${ }^{1}$ Identity exploration focuses on domains such as love, work, and worldviews and mainly takes place during emerging adulthood. ${ }^{9}$ For example, those that struggle with their own identity may be at risk for low self-esteem, depression and anxiety, substance use, and risky sexual behaviors. ${ }^{5,10}$ Additionally, other psychosocial characteristics, like selfefficacy, developed during this time and become important in the establishment of healthy behavioral patterns. ${ }^{6}$ Thus, the unique nature of this developmental period makes it an important age group to study. 


\section{Weight Status}

Currently, the United States is going through an obesity epidemic. ${ }^{8}$ Since $2014,70.7 \%$ of adults aged 20 or older were overweight or obese while obesity in emerging adults has doubled in the past 30 years. ${ }^{11}$ Although obesity is becoming common with increased prevalence rates, those who are overweight experience a myriad of negative outcomes. ${ }^{11}$ These range from physical (i.e. Type 2 diabetes, hypertension, stroke) to emotional (i.e., higher depression, anxiety, low self-esteem, poor body image), and social (i.e., peer rejection, weight-based discrimination). ${ }^{12}$

Weight and Body Image and Self-Esteem

One domain that influences emerging adults well-being is body image. ${ }^{13}$ Body image satisfaction is one's overall opinion or attitudes toward their body figure. ${ }^{14}$ Unfortunately, not all college students feel positive about their bodies. Since the 1980 s, body image dissatisfaction has become common among college students; in fact, up to $90 \%$ of college students say they are concerned about their own body image and these body image concerns are considered normal for college women. ${ }^{13}$ Body image dissatisfaction is associated with symptoms of depression, anxiety, lower self-esteem, and eating disorders. ${ }^{13}$ It has been suggested that society's emphasis on a thin figure contributed to body dissatisfaction among women. ${ }^{15}$ Magazines, television, music videos, and movies are a few ways that society contributes to an unrealistic ideal body image, and constant exposure to these socialized ideals adds to women's struggles for body satisfaction. ${ }^{15}$ More often than not, those that were concerned with their weight had an unrealistic body image for themselves. ${ }^{14}$ Typically, individuals compare their bodies to the ideal body, as well as the bodies of those around them. ${ }^{15}$ Those who constantly compare themselves to others may have more negative mental health outcomes (e.g., lower self-worth/self-esteem). ${ }^{7,13}$ Not only is body image perception subjective, but it can also be manipulated through the influence of others through weight stigma. ${ }^{13}$

The pressure college women face to be thin and attractive contributes to a lower self-esteem among these students. ${ }^{13}$ There are multiple domains of self-esteem, but one that is distorted the most is physical self-worth. This domain of self-esteem is constructed by physical condition, weight concerns, and attractiveness. ${ }^{13}$ Physical self-worth and dissatisfaction is heavily influenced by social ideals and experiences of objectification (called an "internalized third-person perspective" by Mercurio and Landry; 2008, p. 458) of their appearance. ${ }^{16}$ College students who have a weight problem face additional issues that can lower their self-esteem, including peer rejection, depression and anxiety, and weight stigma. ${ }^{14}$ Experiencing body dissatisfaction during this sensitive developmental period can lead to negative health outcomes in adulthood through unhealthy dietary and physical behaviors and substance use. ${ }^{17}$

\section{Weight and Weight Stigma}

With the focus on obesity from the medical and public health fields, the media has also focused on obesity and contributes to weight stigma. ${ }^{8}$ Weight stigma is defined as the social devaluation of individuals perceived to carry excess weight and leads to prejudice, negative stereotyping, and discrimination toward those individuals. ${ }^{18}$ Mass media contributes to anti-fat stereotypes of individuals with obesity through negative portrayals that people with larger bodies are less sophisticated, less intelligent, lazy, weak, and self-indulgent.8,19,20 This further perpetuates assumptions that those with excess weight are lonely, slow, unhappy, ashamed, and sloppy. ${ }^{21}$ In contrast, thin figures are portrayed more positively and assumed to be healthy due to self-control and hard work; therefore perpetuating the assumption that people with an ideal, thin figure are more confident, more attractive, and happier. ${ }^{21}$

Size-based and anti-fat attitudes do not begin in adolescence or adulthood, rather they begin during childhood.21 Overweight children are often rejected by friends because of their excess weight. ${ }^{21}$ Those who are overweight experience teasing and are rated as unpopular which can lead to low self-esteem and body dissatisfaction. ${ }^{21}$ Experiences with weight stigma have negative consequences for physical and psychological well-being that can continue into adulthood including, increased weight and unhealthy weight management behaviors driven by a desire to be thin. ${ }^{21}$

Weight stigma and anti-fat attitudes contribute to poorer physical and mental health. Individuals can experience weight stigma from a variety of sources including medical professionals, employers, police officers, friends, and family. ${ }^{18}$ When women who are overweight or obese experience discrimination because of their weight, they are less likely to engage in physical activity. There are also multiple unfavorable eating behaviors that arise due to weight stigma including overeating, dieting, and eating disorders. ${ }^{18}$ When an individual experiences weight stigma, they are likely to have increased depression, body dissatisfaction, and lower selfesteem. ${ }^{14}$ Examining college students' weight stigma will aid in understanding how to avoid the negative effects of those stereotypes and prevent poor body image and low self-esteem. ${ }^{21}$ 
Present Study

Although weight stigma has garnered attention in the medical fields and has been shown to be related to obesity and self-esteem, research has not yet examined weight stigma as a mediator between weight, self-esteem, and body image. This study utilized a non-experimental correlational design to examine the associations between weight stigma, body image, and self-esteem in female college students of healthy weight and excess weight. The primary aims and hypotheses of this study are:

1. Examine the relationship between body image, self-esteem, weight stigma by weight status. It is hypothesized that body image, self-esteem, and weight stigma will be correlated for women with excess weight, but will not be correlated for women of healthy weight.

2. Examine if there are differences in body image, self-esteem, and weight stigma by weight status (i.e., healthy weight and excess weight). It is hypothesized that women with excess weight will have poorer body image, lower self-esteem, and report greater weight stigma compared to women of healthy weight.

3. Examine if weight stigma mediates the relationship between BMI and self-esteem as well as BMI and body image. It is hypothesized that weight stigma will mediate the relationship between BMI and self-esteem and BMI and body image.

\section{METHODS AND PROCEDURES}

\section{Participants}

The participants in this study were 125 women between the ages of 18 and $25\left(M_{\text {age }}=21.75\right.$; SD $\left.=4.48\right)$ attending various universities across the United States. Of the individuals who completed this study, 5.6\% were Black or African American, 3.2\% Asian or Pacific Islander, 4.8\% Hispanic or Latino, and 83.2\% White or Caucasian. Of the participants, 13\% were freshmen, 24\% were sophomores, $25 \%$ juniors, $11 \%$ seniors, $12 \%$ graduate students, and 15\% were other student status. Eighty percent of the sample identified as heterosexual and $56 \%$ identified as single and not dating.

\section{Procedures}

After obtaining IRB approval, participants were recruited through advertisements in Facebook groups and pages as well as through snowball sampling. The data for this study was gathered in the August to December 2018. Data was collected using a questionnaire created in Qualtrics.

\section{Measures}

1. Demographics. Participants in this study were asked background questions including age, gender, height, weight, race/ethnicity, and year in school. To measure gender, participants were asked which gender they identified most with $(1$ $=$ male; 2 = female $)$. Participants were asked what year they currently are in college $(1=$ Freshman; $2=$ Sophomore; $3=$ Junior; 4 = Senior; 5 = Graduate Student; $6=$ Non-Degree Student; 7 = Other). Racial group was established by asking participants how they would describe their race/ethnicity $(1=$ Black or African American; $2=$ American Indian or Native American; 3 = Asian or Pacific Islander; $4=$ Hispanic or Latino; $5=$ White or Caucasian; $6=$ Multicultural). Participants also reported their sexual orientation $(1=$ heterosexual; $2=$ lesbian; $3=$ gay; $4=$ bisexual; $5=$ questioning; $6=$ queer; $7=$ other $)$ and relationship status $(1=$ single, not dating; $2=$ single, dating multiple people; $3=$ single, but in a committed relationship; $4=$ married; $5=$ divorced; $6=$ separated; $7=$ widowed; $8=$ other).

2. Body Mass Index (BMI). Height was self-reported in feet and inches and weight was also self-reported in pounds. Height and weight were used to calculate BMI for each participant $\left(\mathrm{kg} / \mathrm{m}^{2}\right)$.

3. Self-Esteem. Self-esteem was assessed using a one-item question that stated "I have high self-esteem" and asking participants to rank whether they agree with that statement $(1=$ Strongly agree, $2=$ Agree, $3=$ Neutral, $4=$ Disagree, and 5 = Strongly disagree). This single item has been shown to be as valid and reliable in men and women of various racial/ethnic backgrounds and in college students. ${ }^{22}$

4. Body Shape Questionnaire Short Form (BSQ). The Body Shape Questionnaire was used to evaluate participants’ body image perception with emphasis on "feeling fat." 15,16 This 16-item questionnaire was developed and validated in 1993 and was adapted from the original 34-item questionnaire developed and validated in 1987. The results are found by summing all the items in the questionnaire $(1=$ Never, $2=$ Rarely, $3=$ Sometimes, $4=$ Often, $4=$ Very Often, $5=$ Always; $\alpha=0.95){ }^{23}$

5. Weight Self-Stigma Questionnaire (WSSQ). The Weight-Self Stigma Questionnaire was used in this study to measure the level of stigma associated with obesity. This twelve-question scale will also be used to measure how one perceives their own body image when exposed to experiencing weight discrimination/stigma and internalization of stigma $(1=$ Completely Disagree, $2=$ Mostly Disagree, $3=$ Neither Agree nor Disagree; $4=$ Mostly Agree, $5=$ Completely Agree; $\alpha$ 
$=0.90) \cdot{ }^{18}$ In previous research conducted to validate the scale, it was found that the WSSQ correlates with BMI, psychological distress, and gender. ${ }^{18}$ Total subscale was the sum of all the items. There were two subscales, fear of enacted stigma and self-devaluation. The fear of enacted stigma, referring to external stigma or discrimination experienced by others because of one's weight, was the sun of 1-6. The self-devaluation subscale, referring to attributing negative qualities to oneself in regards to one's weight, was the sum of items 7-12.

\section{Data Analyses}

Before testing the study aims, BMI was divided into healthy weight $(18.5 \leq$ BMI $\leq 24.9)$ and excess weight (BMI $\leq 25)$. Those that reported a low body weight were led to the exit of the survey and thus not included in analyses. To test the first aim examining the relationships between body image, weight stigma, and self-esteem, a series of correlations were run. Correlations were run separately for healthy weight and excess weight. To test the second aim and examine if there were differences in the study variables by weight status, a series of independent samples t-tests were run comparing women of healthy weight and excess weight. To test the third aim examining if weight stigma mediated the relationship between BMI and self-esteem, Hayes' PROCESS, via SPSS v. 24 was used. ${ }^{24}$ After specifying a simple mediation model (model 4), Hayes' PROCESS uses ordinary least squares regression and estimates each path's significance, coefficients, and confidence intervals while also providing direct and total effects of the model.

\section{RESULTS}

Before testing the aims, participants were divided into groups based on BMI. Healthy $(\mathrm{n}=55)$ and excess weight $(\mathrm{n}=62)$ BMIs were determined using Centers for Disease Control defined criteria. To test the first aim, correlations were run separately for each group. As shown in Table 1, for women of healthy weight, self-esteem was negatively associated with body image dissatisfaction and total weight stigma and weight stigma subscales. Indicating that, as body image dissatisfaction and weight stigma increased, self-esteem decreased. Body image dissatisfaction was also significantly positively correlated with weight stigma. As body image dissatisfaction increased so did experiences with weight stigma. Interestingly, the associations between the study variables were in the same directions and of similar magnitude for women with excess weight.

\begin{tabular}{lccccc}
\hline Indicator & 1. & 2. & 3. & 4. & 5. \\
\hline 1. Self-Esteem & - & $-.63^{* *}$ & $-.53^{* *}$ & $-.51^{* *}$ & $-.46^{* *}$ \\
2. BSQ & $-.57^{* *}$ & - & $.67^{* *}$ & $.59^{* *}$ & $.62^{* *}$ \\
3. WSSQ Total & $-.44^{* *}$ & $.73^{* *}$ & - & $.88^{* *}$ & $.92^{* *}$ \\
4. WSSQ Fear & $-.40^{* *}$ & $.69^{* *}$ & $.93^{* *}$ & - & $.62^{* *}$ \\
5. WSSQ Self & $-.43^{* *}$ & $.68^{* *}$ & $.94^{* *}$ & $.75^{* *}$ & - \\
Table 1. Correlations among Study Variables with Healthy Weight below the Diagonal and Excess Weight Above the Diagonal.
\end{tabular}

To test the second aim examining differences in self-esteem, body image, and weight stigma between women of healthy weight and excess weight, independent samples t-tests were run. As shown in Table 2 , there were no significant differences in selfesteem. However, women with excess weight did report significantly greater body dissatisfaction $(t[115]=-3.45, p<.001)$ and weight stigma $(t[115]=-3.19, \mathrm{p}<.01)$. Women with excess weight were also significantly higher on both subscales of the WSSQ, fear $(t[115]=-3.15, p<.01)$ and self-devaluation $(t[115]=-2.735, p<.01)$. Women of healthy weight had significantly higher dislike of fat $(t[115]=2.11, p<.05)$, compared to women's of excess weight.

\begin{tabular}{|c|c|c|c|c|}
\hline & $\begin{array}{c}\text { Total Sample } \\
\mathrm{n}=124\end{array}$ & $\begin{array}{c}\text { Healthy Weight } \\
\mathrm{n}=55\end{array}$ & $\begin{array}{c}\text { Excess Weight } \\
\mathrm{n}=62\end{array}$ & $t$-test \\
\hline Variable & $\mathrm{M}(\mathrm{SD})$ & $\mathrm{M}(\mathrm{SD})$ & $\mathrm{M}(\mathrm{SD})$ & \\
\hline BMI & $26.93(6.53)$ & 21.81(1.51) & $31.47(5.88)$ & -- \\
\hline Self-Esteem & $3.22(1.10)$ & $3.40(1.05)$ & $3.05(1.11)$ & ns. \\
\hline BSQ & $32.17(17.31)$ & $27.06(15.89)$ & $37.68(16.75)$ & $-3.45^{* * *}$ \\
\hline WSSQ & $20.45(10.37)$ & $17.45(10.77)$ & $23.61(8.99)$ & $-3.19^{* *}$ \\
\hline Fear & $10.75(5.38)$ & $9.20(5.61)$ & $12.35(4.63)$ & $-3.15^{* *}$ \\
\hline Self-Dev & $9.69(5.81)$ & $8.25(5.91)$ & $11.25(5.36)$ & $-2.73^{* *}$ \\
\hline
\end{tabular}

Table 2. Means, Standard Deviations, and t-test Results Comparing Women of Healthy Weight and Excess Weight on the Study Variables.

To test the third aim examining if weight stigma mediates the relationship between BMI and self-esteem and BMI and body image, Hayes' mediation model via PROCESS was used for the total sample. Mediation was tested separately for self-esteem and 
body image for the entire sample. The results are shown in Figure 1, Table 3, and Table 4. Hayes' PROCESS estimates pathways $\mathrm{A}$ (the independent variable to the mediator), $\mathrm{B}$ (the mediator to the outcome), $\mathrm{C}$ (the independent variable to the outcome), and C' (the independent variable to the outcome through the mediator).

For the self-esteem, pathways A and B were significant. The total effect of BMI on self-esteem, pathway C, was significant $(b=$ $.97, p<.001)$, while the direct effect, pathway C' (accounting for the mediator), was non-significant $(b=-.01, p=.83)$. Similar results were found in the body image model; pathways A and B were significant. The total effect of BMI on body image, pathway $\mathrm{C}$, was significant $(b=-.03, p=.02)$, while the direct effect, pathway $C^{\prime}$, was non-significant $(b=.28, p=.13)$. Both models showed significant indirect effects (unstandardized total indirect effect $=-.03$, Bootstrapped SE $=.01,95 \% \mathrm{CI}=-.05,-.01$ and unstandardized total indirect effect $=.67$, Bootstrapped $\mathrm{SE}=.16,95 \% \mathrm{CI}=.31, .97$ for self-esteem and body image, respectively).
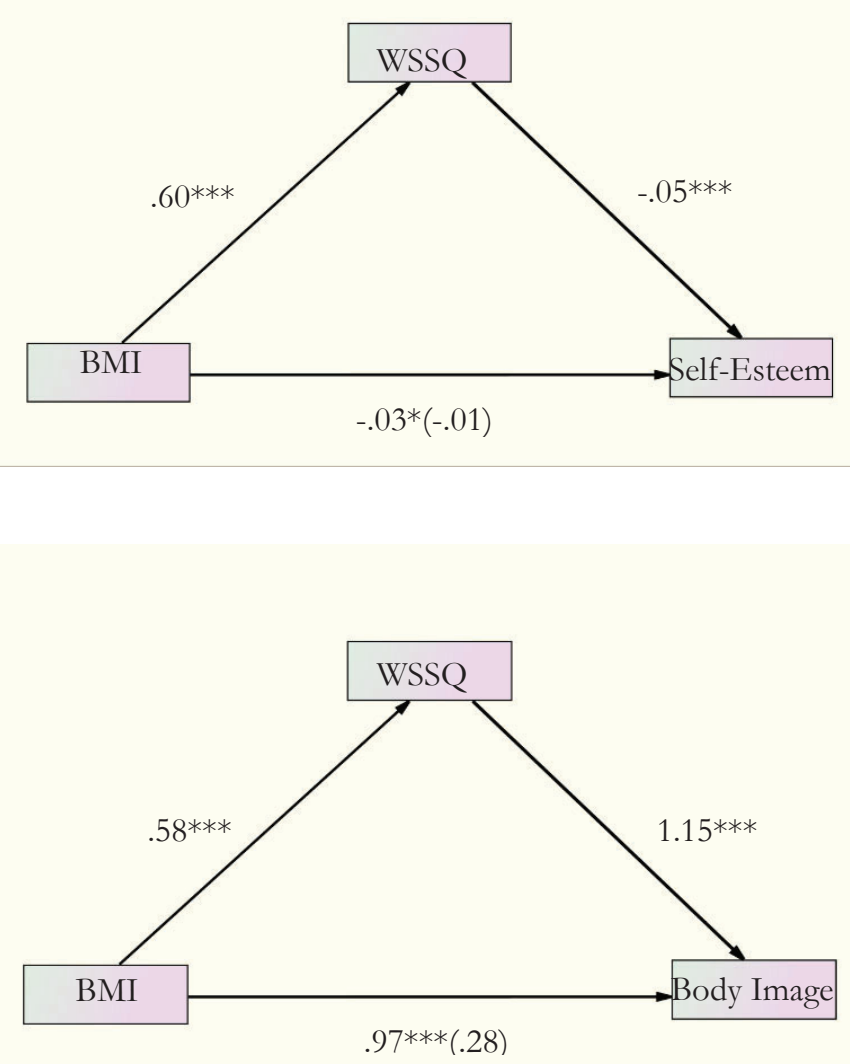

Figure 1. Standardized Regression Coefficients for the Mediation Models Testing Weight Stigma as a Mediator between BMI and Self-Esteem and BMI and Body Image. 
Outcome: WSSQ (Path A)

\begin{tabular}{|c|c|c|c|c|c|}
\hline Predictors & $b$ & SE & $\mathrm{t}$ & $\mathrm{CI}_{\text {lower }}$ & $\mathrm{CI}_{\text {higher }}$ \\
\hline BMI & $.60 * * *$ & .14 & 4.24 & .32 & .87 \\
\hline \multicolumn{6}{|c|}{ Outcome: Self-Esteem (Path B) } \\
\hline & $b$ & SE & $\mathrm{t}$ & $\mathrm{CI}_{\text {lower }}$ & $\mathrm{CI}_{\text {higher }}$ \\
\hline WSSQ & $-.05 * * *$ & .01 & -5.43 & -.07 & -.03 \\
\hline \multicolumn{6}{|c|}{ Outcome: Self-Esteem (Path C) } \\
\hline & $b$ & SE & $\mathrm{t}$ & $\mathrm{CI}_{\text {lower }}$ & $\mathrm{CI}_{\text {higher }}$ \\
\hline BMI & $-.03 *$ & .01 & -2.21 & -.06 & -.01 \\
\hline \multicolumn{6}{|c|}{ Outcome: Self-Esteem (Path C') } \\
\hline & $b$ & SE & $\mathrm{t}$ & $\mathrm{CI}_{\text {lower }}$ & $\mathrm{CI}_{\text {higher }}$ \\
\hline BMI & -.01 & .02 & -.20 & -.03 & .03 \\
\hline WSSQ & $-.05 * * *$ & .01 & -5.43 & -.07 & -.03 \\
\hline
\end{tabular}

Table 3. Mediation Analysis Using Self-Esteem.

Outcome: WSSQ (Path A)

\begin{tabular}{|c|c|c|c|c|c|}
\hline Predictors & $b$ & SE & $\mathrm{t}$ & $\mathrm{CI}_{\text {lower }}$ & $\mathrm{CI}_{\text {higher }}$ \\
\hline BMI & $.58 * * *$ & .13 & 4.18 & .31 & .86 \\
\hline \multicolumn{6}{|c|}{ Outcome: Body Image (Path B) } \\
\hline & $b$ & SE & $\mathrm{t}$ & $\mathrm{CI}_{\text {lower }}$ & $\mathrm{CI}_{\text {higher }}$ \\
\hline WSSQ & $1.15^{* * *}$ & .12 & 9.38 & .91 & 1.39 \\
\hline \multicolumn{6}{|c|}{ Outcome: Body Image (Path C) } \\
\hline & $b$ & SE & $\mathrm{t}$ & $\mathrm{CI}_{\text {lower }}$ & $\mathrm{CI}_{\text {higher }}$ \\
\hline BMI & $.97 * * *$ & .23 & 4.05 & .49 & 1.42 \\
\hline \multicolumn{6}{|c|}{ Outcome: Body Image (Path C') } \\
\hline & $b$ & SE & $\mathrm{t}$ & $\mathrm{CI}_{\text {lower }}$ & $\mathrm{CI}_{\text {higher }}$ \\
\hline BMI & .28 & .18 & 1.51 & -.08 & .65 \\
\hline WSSQ & $1.15^{* * *}$ & .12 & 9.38 & .91 & 1.39 \\
\hline
\end{tabular}

Table 4. Mediation Analysis Using Body Image. 


\section{DISCUSSION}

Developing positive body image and self-esteem are important when it comes to young women's overall well-being. ${ }^{13}$ This study examined the associations between self-esteem, body image, and weight stigma among women of healthy weight and excess weight. Overall, there were strong relationships between self-esteem, body image, weight, and weight stigma. Specifically, lower self-esteem was associated with poorer body image and experiences with weight stigma. Additionally, body image dissatisfaction was associated with more experiences of weight stigma. Interestingly, these relationships were in the same direction and of a similar magnitude for both women of healthy and excess weight. This speaks to everyone feeling the pressure to be thin and even those that are healthy weight are susceptible to unrealistic body image expectations and report experiencing weight stigma. It is interesting that having a lower BMI and being of healthy weight does not exclude an individual from having issues with weight stigma or body shape issues. This is consistent with previous work noting that pressures to be thin or have an ideal body size can have a negative influence on one's self-esteem. ${ }^{5}$ Physical self-worth is constructed by weight concerns and attractiveness and, therefore, can be built by one's level of self-esteem and body image perception. All of these variables have some sort of influence on one another and can have an impact on one's overall mental and physical health. This is important given that emerging adulthood is a critical time to develop positive body image and self-worth as these will be carried forward into adulthood. ${ }^{5,21}$ These results suggest that more research should be done on the effect of weight stigma on not just unhealthy weight individuals, but healthy weight individuals as well.

Although the correlations were similar for women of healthy weight and excess weight, there were significant differences in the study variables by weight status when examined using t-tests. However, there was no difference in self-esteem between women of healthy weight and excess weight. These results are slightly divergent from other studies using adults or children that have noted self-esteem differences between women of healthy weight and excess weight. One possible explanation is that emerging adulthood is a unique time of development - and likely a critical turning point in the life course where behaviors and associated psychosocial well-being have long-term implications.$^{25}$ Emerging adults often struggle with self-esteem, particularly women. Emerging adulthood is also a time marked by heightened identity exploration when women are trying out different behaviors, careers, relationships, and ideologies as they figure out who they want to be., ${ }^{1,9}$ Emerging adult women are particularly vulnerable to issues with self-esteem as they develop their identity and figure out what is important in terms of their overall self-concept. ${ }^{13,15}$ Present study results further suggest that young women are susceptible self-esteem issues - regardless of weight status. Both groups of women (those with excess weight and those of average/healthy weight) showed similar self-perception patterns, suggesting that thin-ideal messages affect all women and are ubiquitous in our media and society. $8,19,20$

There were significant differences in body image and weight stigma for women of healthy weight and excess weight. Specifically, women with excess weight had greater body image dissatisfaction and more experiences with weight stigma. These results are consistent with previous work noting poorer psychosocial health of women with excess weight and the stigma and stereotypes associated with excess weight. ${ }^{13}$ Given the emphasis from society on a thin body shape, it is unsurprising that women with excess weight have greater body image dissatisfaction and experience more weight stigma. Women with excess weight would be uniquely aware that they do not fit with the idealized body through the comparisons women often make to others. The greater body dissatisfaction experienced by women with excess weight is likely due to experiences with weight stigma.

This study also examined if weight stigma mediated the relationship between BMI and self-esteem and BMI and body image. Results showed significant full mediation, meaning that experiencing weight stigma completely accounted for the relationship between BMI and self-esteem and body image. These results support the idea that it is not necessarily an individual's weight that results in their self-esteem but rather it is the stigma society puts on being overweight. Overall, society places an emphasis on a thinner figure for women stating that the thinner you are, the better you are. ${ }^{14}$ Specifically, the stereotype of people with excess weight is that they are lazy, lonely, slow, unhealthy, and sloppy. ${ }^{8}$ If you are thin, you are happy, but if you are overweight, you are unhappy. Women receive these messages from a variety of sources including medical professionals, family and friends, and even from strangers and acquaintances; they then internalize these messages, which impacts the way they feel about themselves, resulting in poor body image and low self-esteem. ${ }^{27}$

\section{Limitations}

In this study, there were various limitations encountered by the researchers. One of the largest limitations of this study was the sample size. Participants were recruited through social media posts and snowball sampling in order to obtain the sample.

Although there were plenty of White women, minority groups were lacking. Additionally, snowball sampling limits the ability of this study to generalize to the population and may introduce sample bias since participants were sharing the survey with their friends who are likely similar to them. Another limitation of the study was that this questionnaire could not be distributed to colleges with a more diverse student population. Had this questionnaire been able to reach other areas, the sample size would 
have had the potential to be more diverse. Additionally, this study used a correlational design, so temporal ordering of effects cannot be established. Finally, this study utilized a single item for self-esteem. While this item has been established as reliable and valid using other studies, ${ }^{22}$ use of a single item does limit variability.

\section{CONCLUSIONS}

Emerging adulthood is a particularly important time for identity development and development of life long physical and psychological health. ${ }^{5,10}$ With greater awareness of increasing trends in overweight and obesity, significant prevention and intervention efforts have been targeted for children, adolescents, and adults. ${ }^{11}$ However, given the vulnerable nature of emerging adulthood as a life course turning point, ${ }^{25}$ combined with the health and weight implications of transitioning out of the family home and into independent living (in college or otherwise), ${ }^{26,27}$ focusing these efforts on women between the ages of 18-25 in ways that address unhealthy youth behaviors and shape adult health practices might have the most impact on national obesity trends and correlated health outcomes. Women are particularly vulnerable to experiencing low self-esteem and poor body image. ${ }^{15}$ Additionally, society places pressures on young women to be thin and shuns women for the perception of being overweight. ${ }^{8,19,20}$ These stigmas of having excess weight become internalized by young women and lead to poor self-esteem. ${ }^{21}$ The present study supports these associations and found significant full mediation. That is, weight stigma completely accounted for the relationship between BMI and self-esteem and BMI and body image. Thus, it appears that it is not an individual's weight that influences how they feel about themselves, but the way they are treated by others.

\section{ACKNOWLEDGEMENTS}

The authors thank Dr. Kristin Jozkowski for her input and assistance in writing the thesis and serving on the Honors Committee. The authors also thank the Dale Bumpers College Honors Program and well as the University of Arkansas Honors College for the opportunity to pursue research. The authors thank everyone who made this manuscript possible, and for all the hard work put into it from all parties.

\section{REFERENCES}

1. Arnett, J.J. (2000) Emerging adulthood: A theory of development from the late teens through the twenties, Am Psychol 55, 469-480. https://doi.org/10.1037//0003-066x.55.5.469

2. Arnett, J.J., and Mitra, D. (2018) Are the features of emerging adulthood developmentally distinctive? A comparison of ages 18-60 in the United States, Emerg Adulthood 70, 569-576. https:/ / doi.org/ 10.1177/2167696818810073

3. National Center for Education Statistics, The Condition of Education 2018, bttps://nces.ed.gov/pubs2018/2018144.pdf (accessed Mar 2019)

4. van der Zanden, P.J., Denessen, E., Cillessen, A.H., and Meijer, P.C. (2018) Domains and predictors of first-year student success: A systematic review, Educational Research Review 23, 57-77. bttps:// doi.org/10.1016/j.edurev.2018.01.001

5. Schwartz, S.J., Hardy, S.A., Zamboanga, B.L., Meca, A., Waterman, A.S., Picariello, S., Luyckx, K., Crocetti, E., Kim, S.Y., Brittian, A.S., Robert, S.E., Whitbourne, S.K., Ritchie, R.A., Brown, E.J., and Forthun, L.F. (2015) Identity in young adulthood: Links with mental health and risky behavior, I Appl Dev Psychol 36, 39-52. https:// doi.org/10.1016/j.appdev.2014.10.001

6. Nelson, M.C., Story, M., Larson, N.I., Neumark-Sztainer, D., and Lytle, L.A. (2008) Emerging adulthood and college-aged youth: an overlooked age for weight-related behavior change, Obesity 16, 2205-2211. bttps:// doi.org/10.1038/oby.2008.365

7. Grossbard, J.R., Lee, C.M., Neighbors, C., and Larimer, M.E. (2009) Body image concerns and contingent self-esteem in male and female college students, Sex Roles 60, 198-207. https:/ / doi.org/10.1007/s11199-008-9535-y

8. Major, B., Hunger, J.M., Bunyan, D.P., and Miller, C.T. (2013) The ironic effects of weight stigma. J Exp Soc Psychol 51, 74-80. https://doi.org/10.1016/j.jesp.2013.11.009

9. Vosylis, R., Erentaite, R., and Crocetti, E. (2018) Global versus domain-specific identity processes: Which domains are more relevant for emerging adults? Emerg Adulthood 6, 32-41. https:// doi.org/10.1177/2167696817694698

10. Persike, M., Seiffge-Krenke, I., Cok, F., Glogowka, K., Pavlopoulos, V., Tantaros, S., Perchec, C., Rohail, I., and Saravia, J.C. (2018) Emerging adults' psychopathology in seven countries: the impact of identity-related risk factors, Emerg Adulthood 67, 116. https:// doi.org/10.1177/2167696818791108

11. Centers for Disease Control, Obesity and Overweight, https:// mww.cdc.gov/obesity/index.html (accessed Mar 2019)

12. Djalalinia, S., Qorbani, M., Peykari, N., and Kelishadi, R. (2015) Health impacts of obesity, Pakistan Journal of Medical Sciences 31, 239-245. https:// doi.org/10.12669/pjms.311.7033

13. Lowery, S.E., Kurpius, S.E.R., Befort, C., Blanks, E.H., Sollenberger, S., Nicpon, M.F., and Huser, L. (2005) Body image, self-esteem, and health-related behaviors among male and female first year college students, J Coll Stud Dev 46, 612-623. bttps://doi.org/10.1353/csd.2005.0062

14. Chang, H.J., and Suttikun, C. (2017) The examination of psychological factors and social norms affecting body satisfaction and self-esteem for college students, Fam Consum Sci Res J 45, 422-437. https:/ / doi.org/10.1111/fcsr.12220 
15. Fitzsimmons-Craft, E.E., Harney, M.B., Koehler, L.G., Danzi, L.E., Riddell, M.K., and Bardone-Cone, A.M. (2012) Explaining the relation between thin ideal internalization and body dissatisfaction among college women: The roles of social comparison and body surveillance, Body Image 9, 43-49. https:/ / doi.org/10.1016/j.bodyim.2011.09.002

16. Mercurio, A.E., and Landry, L.J. (2008) Self-objectification and well-being: The impact of self-objectification on women's overall sense of self-worth and life satisfaction, Sex Roles 58, 458-466. https:/ / doi.org/10.1007/s11199-007-9357-3

17. Neumark-Sztainer, D., Paxton, S.J., Hannan, P.J., Haines, J., and Story, M. (2006) Does body satisfaction matter? Five-year longitudinal associations between body satisfaction and health behaviors in adolescent females and males, $J$ Adolesc Health 39 , 244-251. bttps:// doi.org/10.1016/j.jadohealth.2005.12.001

18. Vartanian, L.R., and Novak, S.A. (2011) Internalized societal attitudes moderate the impact of weight stigma on avoidance of exercise, Obesity 19, 757-762. https:/ / doi.org/10.1038/oby.2010.234

19. Langdon, J., Rukavina, P., and Greenleaf, C. (2016) Predictors of obesity bias among exercise science students, Adv Physiol Educ 40, 157-164. https:// doi.org/10.1152/advan.00185.2015

20. Pearl, R.L., Puhl, R.M., and Brownell, K.D. (2012) Positive media portrayals of obese persons: Impact on attitudes and image preferences, Health Psychol 31, 821-831. https:/ / doi.org/10.1037/ a0027189

21. Greenleaf, C., Chambliss, H., Rhea, D.J., Martin, S.B., and Morrow, J.R. (2006) Weight stereotypes and behavioral intentions toward thin and fat peers among White and Hispanic adolescents, J Adolesc Health 39, 546-552. bttps:// doi.org/10.1016/j.jadohealth.2006.01.013

22. Robins, R.W., Hendin, H.M., and Trzesniewski, K.H. (2001) Measuring global self-esteem: Construct validation of a singleitem measure and the Rosenberg Self-Esteem Scale, Pers Soc Psychol Bull 27, 151-161. https://doi.org/10.1177/0146167201272002

23. The body shape questionnaire (BSQ) and its shortened forms, Revisited, 2011. https:// wmw.psyctc.org/tools/bsq/ (accessed Dec 2018)

24. Hayes, A.F. (2017) Introduction to mediation, moderation, and conditional process analysis: A regression-based approach. Guilford Publications, New York.

25. Elder, G.H. (1998) The life course as developmental theory, Child Dev 69, 1-12. https:// doi.org/10.2307/1132065

26. Becnel, J.N., Zeller, M.H., Noll, J.G., and Peugh, J. (2017) Romantic, sexual, and sexual risk behaviours of adolescent females with severe obesity, Ped Obesity 12, 388-397. https:/ / doi.org/10.1111/ijpo.12155

27. Gillen, M.M., and Lefkowitz, E.S. (2011) Body size perceptions in racially/ethnically diverse men and women: Implications for body Image and self-esteem, N Am J Psychol 13, 1-5. https://doi.org/10.1016/j.bodyim.2013.03.002

\section{ABOUT THE STUDENT AUTHOR}

Carlie Smith is from Meade, Kansas and will graduate in May 2019 from the University of Arkansas with a Baccalaureate degree in Human Development and Family Sciences with a concentration in Child Development. Following graduation, Carlie will be attending Rockhurst University to pursue a Master's Degree in Occupational Therapy.

\section{PRESS SUMMARY}

This article examines the relationships between self-esteem, body image, and weight stigma in female college students. Findings suggest that women that are overweight experience weight stigma that contributes to low self-esteem and poor body image. 